\title{
APRENDIZAGEM BASEADA EM PROBLEMAS E A FORMAÇÃO DO FISIOTERAPEUTA: ESTUDO DE CASO
}

\author{
PROBLEM-BASED LEARNING AND THE TRAINING OF THE \\ PHYSIOTHERAPIST: A CASE STUDY
}

\author{
APRENDIZAJE BASADO EN PROBLEMAS Y LA FORMACIÓN DEL \\ FISIOTERAPEUTA: ESTUDIO DE CASO CLÍNICO
}

\author{
Fabiola Hermes Chesani ${ }^{1}$ \\ Sylvia Regina Pedrosa Maestrelli² \\ Luiz Roberto Agea Cutolo ${ }^{3}$ \\ Rosa Nunes ${ }^{4}$
}

Resumo O objetivo geral do estudo foi investigar limites e possibilidades da aprendizagem baseada em problemas na formação do fisioterapeuta. O estudo caracterizou-se como pesquisa de natureza qualitativa, com os dados coletados por meio de entrevistas e questionários realizados com docentes e discentes de um curso de fisioterapia, além de observações em sala de aula. Os dados foram analisados por meio da análise de conteúdo. Os três blocos temáticos definidos a priori trataram da concepção do processo saúde-doença, percepção e enfoque do currículo. Por fim, indicamos como limites na formação do fisioterapeuta a percepção do processo saúde-doença, falta de bases teóricas, falta de participação dos alunos, diferença de personalidades e estudo individualizado. As potencialidades apontadas relacionam-se a: boa comunicação, trabalho em conjunto promovendo habilidades profissionais, interajuda e discussão de assuntos, como a integração dos conteúdos e o estudo independente. Este trabalho apresentou indícios de que nas formações investigadas há mais limites do que possibilidades no que se refere à formação de um profissional mais crítico, reflexivo e humanista. Ainda reconhecemos a possibilidade do Problem-Based Learning como prática pedagógica em prol de uma formação mais humana e crítica.

Palavras-chave formação profissional; aprendizagem baseada em problemas; fisioterapia.

\begin{abstract}
The overall objective of the study was to investigate limits and possibilities of problem-based learning in the training of the physiotherapist. The study is characterized as qualitative research, and data were collected through interviews and questionnaires conducted with teachers and students of a physical therapy course, in addition to classroom observations. The data were analyzed based on content analysis. The three thematic blocks defined in advance addressed the health-disease process conception, perception, and focus of the curriculum. Finally, we indicate the perception of the health-disease process, the lack of theoretical bases, of student participation, the difference in personalities, and individualized study as limits in the physiotherapist's training. The potentialities pointed out relate to good communication, joint work promoting professional skills, mutual help, and discussion of subjects, such as content integration, and independent studies. This study showed signs that in the training investigated there are more limits than possibilities regarding forming a more critical, reflective, and humanistic professional. We also recognize the possibility of Problem-Based Learning as pedagogical practice in favor of a more humane and critical training.
\end{abstract}

Keywords vocational training; problem-based learning; physiotherapy. 


\section{Introdução}

No contexto da saúde, os métodos de ensino apoiados na aprendizagem por descoberta e significância e que, em sintonia com o discurso corrente entre os educadores e reformadores do ensino superior, se propõem problematizadores são a metodologia da problematização com o Arco de Maguerez e a aprendizagem baseada em problemas ou Problem Based Learning (PBL) (Silva e Delizoicov, 2008). ${ }^{5}$

São muitos os trabalhos sobre o PBL centrados nos efeitos de aprendizagem e no desempenho dos alunos (Gurpinar et al., 2010; Costa et al., 2011; Almeida e Batista, 2011; Andrade et al., 2011; Alimoglu et al., 2011; Aquilante et al., 2011; Francischetti et al., 2011; Anyaehie et al., 2011; Gomes e Rego, 2011; Mezzari, 2011; Gurpinar, Bati e Tetik, 2011; Czabanowska et al., 2012; Sobral e Campos, 2012; Millan et al., 2012; Nanda e Manjunatha, 2013; Almeida e Batista, 2011; Azer et al., 2013; Gurpinar et al., 2013; Meo, 2013; Preet, Ashish e Shriram, 2013; St-Onge et al., 2014; Al-Azri e Ratnapalan, 2014; Alamodi, 2014).

$\mathrm{Na}$ área da fisioterapia, não se encontraram nas fontes consultadas estudos que investigassem os limites e as possibilidades do PBL na formação do fisioterapeuta. Os trabalhos existentes investigam as concepções de alunos, professores ou egressos sobre o ensino baseado em problemas nos cursos de medicina e alguns de enfermagem e de fisioterapia. Os artigos que relacionam o PBL com a fisioterapia são: Efstathiou e Walker (2014), McAllister e colaboradores (2014), Gunn, Hunter e Haas (2012), Rowe (2012), Cusack e O'Donoghue (2012), Riquelme e Velasco (2011), Thavare (2006), Morris (2003) e Reynolds (2003).

Gomes e Rego (2011) relatam que há uma escassez de dados fundamentados sobre o padrão de desempenho dos graduandos em medicina no Brasil, ainda que a maioria dos trabalhos nacionais e internacionais, alguns já citados aqui, tenha como foco as habilidades cognitivas. Somente os trabalhos de Gomes e colaboradores (2009), Gurpinar e colaboradores (2005) e Matsui e colaboradores (2007) relataram atitudes pertinentes à formação profissional. Segundo Gomes e colaboradores (2009), na ótica dos graduados o curso proporcionou uma formação humanista. Gurpinar e colaboradores (2005) verificaram ganhos maiores com relação à saúde pública por parte de estudantes vinculados ao método de PBL. Já Matsui e colaboradores (2007) observaram que estudantes de currículo PBL tinham 3,1 vezes mais interesse em atenção primária à saúde que os demais.

Identificamos que na medicina são poucas as pesquisas que relacionam o PBL com um modelo integral de saúde e com a formação de um profissional humanista, crítico e reflexivo. Se na medicina, área em que o PBL é amplamente difundido, existe tal escassez, na fisioterapia a escassez de estudos sobre o PBL na formação profissional é muito maior. Diante dessa situação, a pesquisa que deu origem a este artigo teve como objetivo investigar os limites e as possibilidades do PBL na formação do fisioterapeuta. 


\section{Construção metodológica}

Com relação à natureza das variáveis pesquisadas, optou-se por uma abordagem qualitativa por meio do estudo de caso, que se deu em um curso de fisioterapia de Portugal no período de abril a junho de 2012. A escola foi eleita pelos autores por motivo de conveniência, porque no Brasil os cursos da área da saúde adotam o modelo misto do PBL, e o modelo adotado na escola de fisioterapia em Portugal é o integral. No modelo misto, algumas unidades curriculares utilizam o PBL, enquanto outras mantêm o formato tradicional; no modelo integrado, todo o currículo é organizado em torno de problemas (Macedo, 2009).

Alunos do curso de fisioterapia do $1^{\circ}$ ao $8^{\circ}$ ano, dois tutores e o coordenador do curso participaram da pesquisa. O coordenador do curso de fisioterapia recebeu e aprovou o projeto de pesquisa. Após sua aprovação, encaminhou-se o projeto ao comitê de ética e pesquisa da Escola de Fisioterapia da cidade do Porto. A coleta de dados teve início somente após a aprovação no Comitê de Ética e Pesquisa da escola onde se realizou a pesquisa e depois do aceite e da assinatura do termo de consentimento livre e esclarecido. Os critérios de inclusão no estudo referiam-se aos tutores e aos alunos que assinassem o termo de consentimento e alunos que estivessem regularmente matriculados no curso de fisioterapia. Optou-se por uma amostragem não probabilística por conveniência, pois as amostras eram selecionadas por pessoas ao alcance do pesquisador e dispostas a responder aos questionários e às entrevistas.

As técnicas de coleta de dados utilizadas na pesquisa foram a observação em sala de aula, questionário e entrevista semiestruturada. Para a coleta de dados, os participantes foram abordados pessoalmente no ambiente da universidade e no horário estabelecido por eles, portanto, face a face. A observação em sala de aula aconteceu de forma naturalista, isto é, quando a constatação dos comportamentos dos indivíduos é realizada nas circunstâncias da vida cotidiana. A preparação das observações envolveu várias reuniões com o coordenador do curso de fisioterapia, o conhecimento das regras da escola, a frequência das sessões tutoriais, a duração, a finalidade, as dimensões a se observar e as formas de registro (manuscrito por meio de um diário de campo e gravador em áudio). Os aspectos que incidiram sobre a observação em sala de aula foram: organização, interação, discurso do professor, discurso dos alunos, clima e atividades educativas.

Após as reuniões, as observações se verificaram em um grupo do $1^{\circ} \mathrm{e}$ do $2^{\circ}$ ano sobre um problema desenvolvido na unidade curricular (disciplina). Para cada unidade curricular ou disciplina há o desenvolvimento de quatro problemas, e para cada um apresentado para a turma são necessárias quatro sessões tutoriais (duas horas por problema), pois para alcançar o propósito da PBL os grupos são estruturados seguindo a metodologia dos sete passos da PBL. Para se desenvolver essa metodologia adequadamente, são necessárias quatro sessões tutoriais de duas horas cada (Iochida, 2001). 
Portanto, foram observadas oito sessões tutoriais, quatro do $1^{\circ}$ ano e quatro do $2^{\circ}$ ano, totalizando 16 horas de gravação.

Uma primeira versão do questionário realizou-se com uma amostra mais reduzida dos respondentes. Com esse procedimento, pôde-se detectar alguns problemas na sua construção -os principais se referiam à passagem da língua portuguesa do Brasil para a de Portugal. Tais falhas foram corrigidas após sua detecção, processo que originou uma versão reformulada do questionário. O questionário definitivo aplicado aos alunos tinha duas páginas devidamente identificadas e era constituído por dez questões abertas. Desenvolveu-se em três blocos de questões, sendo que o primeiro versava sobre saúde e doença. O segundo bloco indagava sobre as potencialidades, as fragilidades, a interdisciplinaridade, o trabalho em equipe e a avaliação das sessões tutoriais, e o terceiro sobre o currículo.

Os questionários foram aplicados na universidade no final da sessão tutorial, com a presença do pesquisador e o tempo previsto de preenchimento de vinte minutos em cada turma. No $1^{\circ}$ ano preencheram-se 35 questionários; no $2^{\circ}, 46$; no $3^{\circ}$ ano, 28; e no $4^{\circ}$, oito. Coletaram-se 122 questionários do $1^{\circ}$ ao $8^{\circ}$ ano, mas cinco foram excluídos porque os alunos deixaram em branco ou a letra estava ilegível. Não foi possível aplicar mais questionários no $8^{\circ}$ período devido ao fato de os alunos estarem realizando estágio no ambiente hospitalar.

Para fins de compreensão, os questionários foram divididos em seis grupos de alunos e denominados no estudo pela letra $\mathrm{Q}$. Os números decimais de $1^{\circ}$ a $4^{\circ}$ representam os anos do curso de fisioterapia; a letra $\mathrm{O}$, os alunos que participaram da observação; e a letra $\mathrm{R}$, os que não participaram da observação. Os números naturais que seguem as letras $(1,2,3)$ representam o número do questionário daquele grupo. Portanto, letra $\mathrm{Q}=$ questionário; $1^{\circ}$ ao $4^{\circ}=$ ano de fisioterapia; $\mathrm{O}=$ observação; $\mathrm{R}=$ remanescente.

Foram entrevistados alunos que estavam no grupo tutorial em que ocorreu a observação. Todas as entrevistas eram agendadas com antecedência e no horário escolhido por eles. As entrevistas começavam com a explicação resumida do projeto e dos seus objetivos e aconteceram individualmente e numa sala fechada. O critério adotado foi o de conciliar um horário para as entrevistas que não excedesse o horário das aulas dos alunos para realizar as entrevistas, mas principalmente por considerarmos a universidade o local mais apropriado para que os entrevistados falassem sobre suas atividades, suas experiências, seus conhecimentos, enfim, que discorressem sobre o tema em questão. Quanto aos possíveis inconvenientes da validade interna das entrevistas, entendeu-se ser de grande valia na modalidade de registro das respostas a gravação em áudio dos discursos. Essas gravações ocorreram somente após o consentimento prévio dos entrevistados, mediante assinatura do termo de consentimento livre e esclarecido, onde foram garantidas a confidencialidade e o anonimato das informações recolhidas, o que permitiu que a entrevistadora 
ganhasse a confiança dos entrevistados. As entrevistas foram posteriormente transcritas, gerando arquivos informatizados.

Com a utilização da técnica de incidentes críticos, foram selecionados para a entrevista apenas dois alunos de cada ano, isto é, dois alunos do $1^{\circ}$ ano e dois do $2^{\circ}$. Esta técnica permite trabalhar, de forma mais rigorosa, com redução da subjetividade em observadores ainda em fase de preparação, e é um meio de observação ocasional, feita por testemunha não envolvida diretamente nos acontecimentos. Aplica-se em episódios que ilustram etapas do desenvolvimento e da aprendizagem (Estrela, 1986). Na área da saúde, essa técnica vem sendo empregada pela enfermagem e pela medicina desde 1988. Na área da saúde, as pesquisas que a utilizam geralmente buscam situações comportamentais, como erros na assistência em saúde, avaliação de competência para alguma atividade e indicadores de qualidade na área da gestão. Ao refletir a respeito dos componentes fundamentais dessa técnica, optamos na pesquisa por eleger como incidentes críticos aqueles alunos que tinham atitudes extremas nas sessões tutoriais - portanto, o que era mais comunicativo e o que era menos comunicativo. Este critério foi eleito porque, para o PBL, a mediação do saber é construída pelo professor ocupando o lugar de interlocutor e estabelecendo permanente articulação com o processo de construção do conhecimento com o aluno. Ao se conceber que o aluno é o centro da aprendizagem e que o docente ocupa um lugar que vai além da facilitação, nesse caminho alteraram-se os papéis atribuídos a alunos e professores, pois ambos ocupam lugares de sujeitos em formação que interagem com o conhecimento sistematizado a partir de um olhar crítico e prospectivo.

A entrevista com os alunos seguiu o mesmo roteiro das questões do questionário. Também foram entrevistados o coordenador do curso de fisioterapia e os tutores dos grupos em que se deu a observação naturalista, do $1^{\circ}$ ano e do $2^{\circ}$. Portanto, entrevistaram-se quatro alunos eleitos pela técnica de incidentes críticos, dois tutores e o coordenador.

As entrevistas estão representadas pela letra E. Quando se referem aos tutores, pela letra $\mathrm{T}$; ao ano do curso de fisioterapia, pelo número decimal $1^{\circ}$ ou $2^{\circ}$; e ao coordenador, pela letra C. A descrição da entrevista dos alunos está representada pela letra $\mathrm{A}$, e o ano pelos números decimais $1^{\circ}$ e $2^{\circ}$. $\mathrm{O}$ aluno que mais participou da sessão tutorial, observada pela pesquisadora, é representado pela letra $\mathrm{P}$, e o que menos participou, pela letra M. Resumidamente: $\mathrm{E}=$ entrevista; $\mathrm{T}=$ tutor; $1^{\circ}$ ou $2^{\circ}$ ano do curso de fisioterapia; $\mathrm{C}=$ coordenador; $\mathrm{A}=$ aluno; $\mathrm{P}=$ participativo; $\mathrm{M}=$ menos participativo.

Os dados coletados foram examinados de acordo com a análise do conteúdo(Bardin, 2011). No estudo aqui apresentado, optou-se pela análise do conteúdo latente por ser dinâmica e social. O projeto de pesquisa foi aprovado pelo Comitê de Ética em Pesquisa da Escola Superior de Saúde Politécnica do Porto com o parecer n. 0525/2012. 


\section{Os discursos dos atores envolvidos}

A estratégia para o tratamento dos dados dos questionários e das entrevistas envolveu a redução de dados, a apresentação deles e as conclusões. Relativamente à redução dos dados, iniciou-se por traduzir as entrevistas para a linguagem escrita, as transcrições. No sentido de manter o anonimato, estabeleceu-se um roteiro de codificação, associando os entrevistados a uma referência alfabética e numérica.

Os três blocos de questões desenvolvidos nos questionários e nas entrevistas foram denominados de blocos temáticos. Apresentaram-se os resultados em blocos temáticos, a priori, e em categorias e subcategorias, a posteriori. Não houve separação entre uma técnica de coleta de dados e outra, pois o objetivo do estudo foi construir um panorama crítico sobre o PBL na formação do fisioterapeuta, e não confrontar falas dos participantes. Além do mais, as falas foram muito similares entre um grupo e outro e entre uma técnica e outra, isto é, entre as entrevistas e os questionários. O Quadro 1 demonstra os resultados dos blocos temáticos, das categorias e das subcategorias e os instrumentos de coleta de dados da pesquisa.

\section{Quadro 1}

\begin{tabular}{|c|c|c|c|}
\hline \multicolumn{4}{|c|}{ Grupo de blocos temáticos, categorias, subcategorias e instrumentos de coleta de dados } \\
\hline Bloco temático & Categoria & Subcategoria & $\begin{array}{l}\text { Instrumentos de } \\
\text { coleta de dados }\end{array}$ \\
\hline \multirow[t]{7}{*}{$\begin{array}{l}\text { A. Concepção do } \\
\text { processo saúde/doença }\end{array}$} & $\begin{array}{c}\text { A.1. Saúde como ausência } \\
\text { de doença }\end{array}$ & & Entrevistas e questionários \\
\hline & A.2. Saúde como bem-estar & & Entrevistas e questionários \\
\hline & $\begin{array}{l}\text { A.3. Saúde relacionada aos } \\
\text { determinantes sociais }\end{array}$ & & Entrevistas e questionários \\
\hline & A.4. Percepção do sujeito & & Entrevistas e questionários \\
\hline & & B.1.1 .Bases teóricas & Entrevistas e questionários \\
\hline & B1. Aprendizagem & B.1.2. Relação teoria e prática & Entrevistas e questionários \\
\hline & & B.1.3. Tempo de estudo & Entrevistas e questionários \\
\hline \multirow[t]{3}{*}{ B. Percepção do PBL } & & B.1.4. Estudo independente & Entrevistas e questionários \\
\hline & & B.1.5. Trabalho em grupo & Entrevistas e questionários \\
\hline & B2. Interdisciplinaridade & $\begin{array}{l}\text { B.2.1. Equipe multidisciplinar } \\
\text { como trabalho em equipe }\end{array}$ & Entrevistas e questionários \\
\hline \multirow[t]{2}{*}{ C. Enfoque do currículo } & C.1. Ênfase reabilitadora & & Entrevistas e questionários \\
\hline & $\begin{array}{c}\text { C.2 Promoção da saúde da } \\
\text { população }\end{array}$ & & Entrevistas e questionários \\
\hline
\end{tabular}

Fonte: Os autores.

No bloco temático 'Concepção do processo saúde/doença', relacionou-se o número de alunos e os anos do curso de fisioterapia com as categorias 'saúde como ausência de doença', 'saúde como bem-estar' e 'saúde relacionada com os determinantes sociais em saúde' (DSSs) (Tabela 1). 
Tabela 1

\begin{tabular}{|c|c|c|c|c|c|c|}
\hline $\begin{array}{l}\text { Ano do curso } \\
\text { de fisioterapia }\end{array}$ & $\begin{array}{l}\text { Alunos que } \\
\text { entendem a } \\
\text { saúde como } \\
\text { ausência de } \\
\text { doença }\end{array}$ & $\begin{array}{c}\text { Porcentagem } \\
\text { de alunos que } \\
\text { entendem a saúde } \\
\text { como ausência } \\
\text { de doença }\end{array}$ & $\begin{array}{l}\text { Alunos que } \\
\text { entendem a } \\
\text { saúde como } \\
\text { bem-estar }\end{array}$ & $\begin{array}{c}\text { Porcentagem } \\
\text { de alunos que } \\
\text { entendem a saúde } \\
\text { como bem-estar }\end{array}$ & $\begin{array}{c}\text { Alunos que } \\
\text { entendem a } \\
\text { saúde como os } \\
\text { determinantes } \\
\text { sociais }\end{array}$ & $\begin{array}{c}\text { Porcentagem } \\
\text { de alunos que } \\
\text { entendem a saúde } \\
\text { como os determi- } \\
\text { nantes sociais }\end{array}$ \\
\hline $1^{\circ}$ ano: 37 & 16 & $47 \%$ & 12 & $35 \%$ & 6 & $18 \%$ \\
\hline $2^{\circ}$ ano: 48 & 13 & $31 \%$ & 27 & $64 \%$ & 2 & $5 \%$ \\
\hline $3^{\circ}$ ano: 28 & 9 & $36 \%$ & 15 & $60 \%$ & 1 & $4 \%$ \\
\hline $4^{\circ}$ ano: 8 & 5 & $62 \%$ & 3 & $38 \%$ & 0 & $0 \%$ \\
\hline Total 121 & 43 & $39,50 \%$ & 57 & $52,50 \%$ & 9 & $8 \%$ \\
\hline
\end{tabular}

Fonte: Os autores.

Na Tabela 1, percebe-se um predomínio na forma de se pensar a saúde como a ausência de doença (43) e como bem-estar (57), isto é, 100 (92\%) participantes da pesquisa pensavam dessa forma. Um predomínio que se verificou do $1^{\circ}$ ao $4^{\circ}$ ano do curso de fisioterapia.

Quando comparado com os outros anos, os alunos do $1^{\circ}$ ano apresentaram uma porcentagem maior da compreensão da saúde como ausência de doença, e outros $35 \%$ tinham a ideia de bem-estar, mas para seis participantes a ideia de saúde com os DSS era nítida. No $2^{\circ}$ ano, a percepção da saúde com o bem-estar era bem clara, e apenas dois (5\%) relacionaram a saúde com os DSSs. No $3^{\circ}$ ano, identificaram-se o mesmo predomínio para a compreensão no bem-estar e apenas um (4\%) com os DSSs. Mesmo diante da amostra pequena do $4^{\circ}$ ano, houve um predomínio na percepção da saúde como ausência de doença.

A preocupação com a saúde está melhorando lenta e progressivamente foi o que pareceu do $1^{\circ}$ ao $3^{\circ}$ ano. Entendeu-se que essa melhora estivesse relacionada aos problemas encontrados na estruturação do modelo integral de PBL, uma vez que os alunos do $4^{\circ}$ ano compunham a primeira turma do curso de fisioterapia formada pelo modelo do PBL integral. Já os alunos do $1^{\circ}$ ano vivenciaram algumas mudanças promovidas pela coordenação do curso e pelos tutores ao detectarem alguns problemas na adaptação ao método integral. Portanto, essa divergência na forma de ver e pensar a saúde pode ser novidade pela juventude do método integral no curso, e talvez os tutores estivessem percebendo a necessidade de direcionar a saúde para os DSSs.

Na categoria saúde como ausência de doença, percebeu-se que esse modo de ver e pensar saúde ainda correspondia ao modelo biomédico e se distanciava do reconhecimento do ser humano para além de um conjunto de órgãos e sistemas que apresenta lesões ou disfunções, as quais podem ser resolvidas com o auxílio de outros recursos diferentes dos tecnológicos. 
Saúde é o estado da pessoa, enquanto que doença é um determinado problema que a pessoa tenha, quer psicológico, físico ou mental $\left(\mathrm{Q} 1^{\circ} \mathrm{R} 3\right)$.

Doença não é o estado perfeito, não está com o estado de saúde perfeito, porque se tiver uma entorse tem dor e algo não está bem consigo, não está bem, pois está com dores $\left(\mathrm{EA} 2^{\circ} \mathrm{M}\right)$.

O processo saúde-doença é compreendido como a ausência de patologia (Q3²6).

Esse modelo está aquém das necessidades de saúde das pessoas, pois cada indivíduo é singular e exprime essa singularidade de forma diferente: mora em determinada comunidade com ambiente específico, com sua família ou não, com certos hábitos e costumes, com sua raça, credo, profissão, forma de ser e de expressar suas angústias, tristezas, medos, alegrias, paixões, tensões etc. Quando identificamos essas características, estamos percebendo as necessidades de saúde desse indivíduo. O profissional que não reconhece tais singularidades e percebe o sujeito apenas como uma doença em determinado órgão ou sistema deverá ampliar o seu olhar. A saúde é “a margem de tolerância às infidelidades do meio"; nesse sentido, a saúde implica poder adoecer e sair do estado patológico (Canguilhem, 2006, p. 45). Em outras palavras, a saúde é entendida por referência à possibilidade de se enfrentar situações novas. A doença não é apenas o desaparecimento de uma ordem fisiológica, mas o aparecimento de uma nova ordem vital. O patológico implica pathos, um sentimento direto e concreto de sofrimento e de impotência, sentimento de vida contrariada. A saúde, por sua vez, envolve muito mais que a possibilidade de viver em conformidade com o meio externo: implica a capacidade de instituir novas normas (Canguilhem, 2006).

Os dados mostraram também que $52,50 \%$ dos alunos relacionaram a saúde com bem-estar:

Saúde é o bem-estar emocional, físico e social, sendo que a doença se caracteriza por uma alteração nestes domínios $\left(\mathrm{Q} 4^{\circ} 6\right)$.

Saúde é quando uma pessoa está bem consigo própria fisicamente, emocionalmente ou mentalmente. É a união das três, e isto se chama saúde. Quando uma delas não está na melhor fase, por exemplo, parte física, uma doença, estando uma delas mal, a saúde em si não está bem. É na constituição das três as pessoas com saúde $\left(\mathrm{EAl}{ }^{\circ} \mathrm{P}\right)$.

O termo bem-estar está relacionado com o momento após a Segunda Guerra Mundial, em 1946, quando a Organização Mundial da Saúde (OMS) apresentou o seguinte conceito de saúde: "Saúde é o estado de completo bem-estar físico, mental e social, e não meramente a ausência de doença ou incapacidade" 
(OMS, 1946, p. 1, apud Segre e Ferraz, 1997). Na época, esta definição foi um avanço para a saúde, pois tinha uma visão mais ampla e positiva da saúde e incluía fatores como alimentação, atividade física e acesso aos sistemas de saúde.

Atualmente, a compreensão de saúde vai muito além do conceito apresentado. Quando se expressa a saúde como estado completo, quer dizer, na sua totalidade, esta expressão é de caráter utópico e inalcançável, pois quem tem completo bem-estar físico e mental? Por exemplo: quem usa óculos de grau não tem completo bem-estar físico, e isso não quer dizer que seja uma pessoa doente; na realidade, ela tem saúde e está enfrentando uma alteração no seu sistema ocular. Além do mais, o termo 'bem-estar' indica um estado engessado do processo saúde-doença, pois o indivíduo não permanece constantemente em estado de bem-estar. Uma pessoa, na sua existência, não vive sem angústias ou conflitos, e tais sensações são inerentes à própria história de cada ser humano e de cada sociedade. Para Canguilhem (2006), as infidelidades do meio, os fracassos, os erros e o mal-estar formam parte constitutiva de nossa história, e desde o momento em que nosso mundo é um mundo de acidentes possíveis, a saúde não poderá ser pensada como carência de erros e sim como a capacidade de enfrentá-los. Assim, esse conceito é inatingível e não pode ser usado como meta pelos serviços de saúde atuais nem como preceito dos profissionais de saúde, em constante formação.

Atualmente, o conceito ampliado de saúde é o que contempla as necessidades e exigências da população e do sistema vigente. O conceito ampliado é a resultante das condições de alimentação, habitação, educação, renda, meio ambiente, trabalho, transporte, emprego, lazer, liberdade, acesso e posse da terra e acesso aos serviços de saúde (Brasil, 1987).

Na categoria saúde relacionada aos determinantes sociais, os dados revelaram que dos 121 participantes da pesquisa somente nove $(7,43 \%)$ relacionaram a saúde com os determinantes sociais.

Saúde engloba não só a patologia, mas todo o ambiente que envolve o indivíduo (Q38).

Para mim a saúde não é a ausência de uma doença. Saúde é algo muito mais abrangente, social, psicológico, cultural, ecológico, que a pessoa se sinta bem consigo e no meio em que está. Ou seja, para mim, ser fisioterapeuta muitas vezes para conseguirmos intervir no movimento não é só na pessoa, também temos que intervir em termos de meio ambiente, no que levou a alteração de movimento e nas barreiras que aquela pessoa tem, o que eu posso mudar $\left(\mathrm{ET}^{\circ}{ }^{\circ}\right)$.

Os determinantes sociais da saúde surgiram no século $\mathrm{XX}$, quando se percebeu que a epidemia comportamental e a teoria unicausal deixaram de resolver os problemas. Nesse contexto, emergiram os principais conceitos da segunda revolução da saúde, 'promoção da saúde e estilo de vida'. Os determi- 
nantes reapareceram com a Carta de Ottawa, lançada durante a $1^{a}$ Conferência Internacional sobre Promoção da Saúde, em 1986. As recomendações gerais dos determinantes sociais de saúde eram: melhorar as condições de vida cotidianas, ou seja, as circunstâncias em que as pessoas nascem, crescem, vivem, trabalham e envelhecem; abordar a distribuição desigual de poder, dinheiro e recursos; quantificar e compreender o problema e avaliar o impacto da ação, isto é, alargar a base de conhecimento; desenvolver um corpo de recursos humanos formado sobre os determinantes sociais da saúde; e promover a consciência pública sobre o tema (Pellegrini Filho, 2011).

Na pesquisa aqui apresentada, verificou-se pouca percepção dos alunos do curso de fisioterapia em relação à saúde e seus determinantes. A percepção predominante dos alunos do $1^{\circ}$ ao $4^{\circ}$ ano ainda foi a da saúde relacionada com a doença e com o bem-estar. É preciso que se formem recursos humanos conscientes sobre os determinantes sociais da saúde, tanto no Brasil quanto em Portugal, com fortalecimento na formação do fisioterapeuta sobre os DSSs.

O estudo de Moraes e Manzini (2006) analisou as concepções de dois docentes gestores, 12 docentes tutores e 12 estudantes da $1^{\text {a }}$ série do curso de medicina com referência ao PBL no currículo da Faculdade de Medicina de Marília (Famema), em 2002, e sua relação com a formação médica. A análise dos dados desse estudo permitiu considerar que

a saúde da pessoa não envolve só o bem-estar físico e que o médico, para cuidar de uma pessoa, precisa conhecê-la e ao seu contexto de vida, porque os conhecimentos só sobre o biológico ou sobre os tratamentos medicamentosos e/ou cirúrgicos não são suficientes (Moraes e Manzini, 2006, p. 126).

O conceito de acesso aos cuidados de saúde é um pilar fundamental das políticas de saúde em Portugal. No entanto, ao contrário do que se poderia pensar, trata-se de uma ideia complexa e multifacetada. No nível mais básico, o acesso depende apenas da oferta de cuidados, isto é, da sua disponibilidade. Havendo oferta adequada, a população tem oportunidade de utilizar os serviços. Nesse sentido, o acesso aos cuidados de saúde é essencialmente uma questão de permitir a admissão das pessoas ao seu potencial de saúde e, em consequência, deve ser analisado à luz das necessidades e dos contextos econômicos e culturais dos diferentes grupos da sociedade (Furtado e Pereira, 2010).

Para a OMS (1946, apud Segre e Ferraz, 1997), todas as pessoas devem poder atingir o seu potencial máximo de saúde sem que as circunstâncias econômicas e sociais de cada uma determinem a consecução desse objetivo. Assim, a equidade em saúde pode ser definida como a ausência de diferenças sistemáticas - e potencialmente evitáveis - em um ou mais aspectos, entre grupos populacionais caracterizados social, geográfica ou demograficamente. No âmbito da elaboração do Plano Nacional de Saúde 2010-2016, foi solicitada, 
na perspectiva de melhoria da equidade, uma análise das desigualdades no acesso aos cuidados de saúde (Furtado e Pereira, 2010)

O sistema de saúde português tem apostado a sua intervenção em duas estratégias: centrar as intervenções na família e no ciclo de vida e abordar os problemas por meio de uma aproximação à gestão da doença. Dando continuidade ao Plano Nacional de Saúde 2004-2010, o Observatório do Quadro Comunitário de Apoio apresenta uma visão para o futuro do setor em Portugal - denominada de 'Saúde 2015' - em que se reforça a necessidade de "um sistema de saúde que promova a iniciativa e a autonomia individual e os princípios da coesão social" (Portugal, 2004, p. 2.421).

O Plano Nacional de Saúde 2004-2010 estabelece como uma das orientações estratégicas para a gestão da mudança 'reorientar o sistema de saúde', referindo que os investimentos previstos no sistema de saúde deverão contemplar ou providenciar ao cidadão um atendimento de qualidade, em tempo útil (melhoria do acesso), com efetividade, humanidade e custos sustentáveis ao longo do tempo, com valores individuais e coletivos. Atendimento que esteja centrado num 'novo serviço público' atento às pessoas e aos profissionais de saúde, assegure formas de articulação entre os setores público, social e privado, compatíveis com os objetivos do sistema de saúde e com a qualidade dos instrumentos de governação disponíveis (Sousa, 2009).

Na categoria percepção do sujeito, alguns alunos do $1^{\circ}$ ao $4^{\circ}$ ano confundiram o sujeito com a própria doença, aproximando-se da visão biológica e patológica e distanciando-se da visão de sujeito integral, relacionada aos determinantes sociais em saúde.

Acho que é uma pessoa que precisa de nossa ajuda, que aparece com uma patologia ou um problema qualquer, e nós temos que tentar melhorar a condição de saúde dessa pessoa $\left(\mathrm{EAl}^{\circ} \mathrm{M}\right)$.

Um utente é uma pessoa que requer um profissional de saúde porque apresenta algum problema de saúde $\left(\mathrm{Q}^{\circ} 2\right)$.

Acreditamos que essa percepção do sujeito está articulada à forma de os alunos perceberem a saúde como ausência de doença e como bem-estar. Desse modo eles não conseguem ver o paciente como sujeito; veem o paciente como a doença, e a tendência desse profissional é focar na reabilitação.

Consideramos compreensível que os alunos entendam o sujeito como a própria doença, pois para eles o conceito de saúde está enraizado no modelo biomédico. As mudanças são urgentes na área da saúde. Enquanto não houver a apreensão do conceito atualizado em saúde, será difícil separar o sujeito da própria doença e começar a compreendê-lo com os DSSs. Pensamos que o passo inicial seria o 'saber', e esse 'novo saber' orientaria para novas formas 
de se organizar o 'fazer' e compreender o 'ser'. Aí, sim, teríamos uma verdadeira transformação de um modelo de saúde biomédico e centrado na doença para um modelo integral e centrado na saúde - portanto, uma mudança do paradigma positivista para o antipositivista.

$\mathrm{Na}$ categoria aprendizagem, os discentes do $1^{\circ}$ ao $3^{\circ}$ ano e os docentes relataram algumas possibilidades do PBL, como a integração dos conteúdos, a avaliação formativa, o estudo independente e o maior raciocínio.

Integra várias coisas ao mesmo tempo, não é tudo separado. Quando temos um problema, sabemos, conseguimos integrar anatomia, fisiologia, e integramos isto com a fisioterapia, e não é tudo separado, e conseguimos ligar os conceitos e a fisiologia como base para a fisioterapia $\left(\mathrm{EA} 2^{\circ} \mathrm{M}\right)$.

Funciona com evidência, utiliza experiências passadas, raciocínios para melhorar das próximas vezes. $\mathrm{O}$ fato de muita aprendizagem ser feita por nós e o fato de haver muito componente de avaliação contínua e gradual proporciona uma evolução mais rápida e depende de nós $\left(\mathrm{Q} 2^{\circ} \mathrm{O} 21\right)$.

Os objetivos educacionais são a aprendizagem ativa (apresentação de pergunta e busca de respostas), a aprendizagem integrada (problemas cujas soluções só são possíveis mediante o conhecimento de várias áreas), a aprendizagem cumulativa (de problemas menos complexos para mais complexos) e aprendizagem para a compreensão (reflexão, feedback e prática) (Gomes e Rego, 2011).

Quando o discente relatou que "integra várias coisas ao mesmo tempo e gradualmente", entendemos que existe uma base de conhecimento integrada e estruturada e aprendizagem com autonomia. Quando os docentes relataram que o aluno "é mais ativo, mais responsável, que a PBL promove a integração dos conteúdos", percebemos que existe uma consonância na possibilidade de um Problem Based Learning com base de conhecimentos integrada e estruturada, e com trabalho autônomo.

Já o tutor aproximou o PBL "do gostar de investigar". Entendemos, com base nesta fala, que existe uma relação direta na metodologia dos sete passos do PBL com o percurso da pesquisa científica. Dessa forma, os estudantes aprendem os conteúdos segundo a mesma lógica de uma pesquisa científica, uma vez que, a partir de um problema, constroem hipóteses e buscam dados que são analisados e discutidos até se chegar a uma conclusão.

Tais possibilidades são muito importantes, pois refletem o objetivo principal e educacional do PBL. O objetivo principal é a aprendizagem de uma base de conhecimentos integrada e estruturada em torno de problemas reais e o desenvolvimento da habilidade de aprendizagem autônoma e de trabalho em equipe. 


\section{Percepção dos atores sobre a aprendizagem}

Na categoria aprendizagem, encontramos cinco subcategorias: bases teóricas, relação teoria e prática, tempo de estudo, estudo independente e trabalho em grupo.

Na subcategoria 'bases teóricas', percebemos que os alunos do $1^{\circ}$ ao $4^{\circ}$ ano e os tutores pensavam de forma similar: deficiências no aprofundamento teórico das disciplinas denominadas básicas (anatomia, fisiologia, fisiopatologia), indicando um limite do PBL reforçado pela fala a seguir:

São fragilidades que se situam em dois níveis: um tem a ver com as características genéricas do PBL, que é o estudo com mais profundidade e mais consolidado, e isto tem um preço, e o preço é que se tende a cobrir menos assuntos, dá-se menos matéria que é coberta, e isto pode ser entendido como um problema. A literatura descreve que os estudantes que fazem o programa do PBL tendem a ter menor abrangência de conteúdos. Isto está a acontecer, embora na transição de um modelo para outro não se tenha dado tantos conteúdos. Perde-se sempre quando há menos conteúdos cobertos. E como o objetivo do curso está centrado nas situações problemas e não nas matérias e nem disciplinas, a tendência é se perder alguma coisa (EC).

Vários autores apontam a falta de bases teóricas como uma desvantagem do PBL. Kalaian, Mullan e Kasim (1999) confirmam a superioridade dos cursos tradicionais nos resultados concernentes às ciências básicas com relação à avaliação da National Board of Medical Examination Performance.

Os aspectos negativos relatados no estudo de Moraes e Manzini (2006) apontam que os estudantes se concentraram na falta de conteúdos teóricos das ciências básicas, conteúdos normalmente valorizados nas primeiras séries do curso médico, e explicitaram a dificuldade inicial de aprender a estudar sozinhos tais conteúdos, ou seja, de encontrar recursos para superar suas dificuldades na autoaprendizagem. Um docente que participou da pesquisa apresentou preocupação com o conteúdo das disciplinas básicas, por ser pontual e superficial nos problemas.

Willis e colaboradores (2003) aplicaram um questionário específico para habilidades e competências profissionais médicas em dois grupos: um grupo graduado em medicina pelo ensino tradicional e outro de graduandos no modelo PBL. Este estudo mostrou que os alunos do modelo PBL entendiam menos sobre o processo saúde-doença, ou seja, no grupo tradicional o estudo do processo saúde-doença parecia ser mais bem conduzido.

Em nosso estudo, o tutor do $1^{\circ}$ ano relatou que a responsabilidade por essa falta de conhecimentos teóricos devia-se à imaturidade do aluno diante do novo, isto é, à mudança do modelo tradicional para o modelo do PBL. Durante 14 anos de sua vivência escolar, o aluno aprende de forma tradicional, em que o centro é o professor, e agora o aluno é o centro do seu aprendizado. 
Para sanar essa limitação do PBL, deveria haver uma transição de um modelo para o outro e um apoio mais aprofundado no ensino das disciplinas básicas. Para esse tutor, o modelo misto seria o ideal.

O próprio PBL puro coloca o aluno ativo na busca do saber, na construção do conhecimento. É preciso um conhecimento de base e depois ter uma maturidade. Para mim, choca um bocadinho que eles vêm de um regime tradicional secundário e passam para o ensino superior num modelo totalmente diferente. Acho que deve haver uma transição. Acredito num modelo que vai buscar um bocadinho dos dois. Deve haver aí uma fase de transição, aquilo que são as matérias básicas e que dão suporte, que vão construir um raciocínio em várias áreas da fisioterapia, anatomia, bioquímica, biofísica, fisiologia, biomecânica $\left(\mathrm{ETl}^{\circ}\right)$.

Gil (2006) também entende que uma das limitações do PBL é o desempenho de papéis novos dos estudantes e confirma a fala do tutor 1 de que a experiência do aluno no decorrer do ensino fundamental e médio vem do professor, por meio de aulas expositivas, e que esse é o problema mais frequente nos primeiros anos dos cursos que adotam o PBL de forma integral. Esse autor compartilha ainda das ideias do tutor 1, segundo o qual, para que seja sanada tal limitação, os alunos poderiam ter aulas expositivas e leituras.

Quanto ao tempo de estudo, os acadêmicos relataram:

O fato de termos de realizar sínteses após as sessões tutoriais, perdemos muito tempo com elas, enquanto poderíamos estar a utilizar para estudar outras áreas $\left(\mathrm{Q} 1^{\circ} \mathrm{R} 3\right)$.

Dá muito trabalho procurar todas as informações dos problemas e se perde muito tempo e às vezes não procuramos melhores sítios $\left(\mathrm{EAl}^{\circ} \mathrm{P}\right)$.

Quanto ao grande tempo de estudo de que os alunos do $1^{\circ}$ e do $2^{\circ}$ ano necessitavam para realizar as atividades solicitadas pelos tutores, acreditamos que esteja coerente com a proposta de adaptação para o modelo de ensino, pois os alunos do $3^{\circ}$ e do $4^{\circ}$ ano não mencionaram o excesso de tempo como limite do PBL. O Problem Based Learning requer um tempo considerável para formular os problemas, preparar o material, coletar, analisar e interpretar os dados e avaliar o aprendizado dos estudantes. Se o aluno não disponibilizar esse tempo, o estudo fica deficitário.

No que diz respeito à relação entre teoria e prática, os alunos e os docentes entenderam que era adequada. Acreditamos que essa relação aconteça por meio do problema, ou seja, um caso clínico não resolvido que é ponto de partida dos alunos na busca pelo conhecimento e, posteriormente, na aplicação desse conhecimento em outro problema. O problema é o disparador da 
sessão tutorial e está relacionado com questões epidemiológicas, conforme relatou o tutor do $1^{\circ}$ ano:

É o gatilho para se lançar as questões. A decisão dos problemas tem um componente epidemiológico, para articular mais com a prática $\left(\mathrm{ETl}^{\circ}\right)$.

Procuramos evidenciar, nas falas dos alunos e dos tutores, que o estudo independente é uma das possibilidades, e essa característica faz parte do objetivo principal do PBL, citado anteriormente: o desenvolvimento de habilidade de aprendizagem autônoma.

Promover o espírito de equipe e o trabalho de grupo. Fomentar a autoaprendizagem e a resolução de problemas por nós próprios. Trabalho em grupo e autonomia (Q3²8).

Em suas pesquisas, Hill e colaboradores (1998), Hoffman e colaboradores (2006), Koh e colaboradores (2008) e Preet, Ashish e Shriram (2013) também destacam como possibilidade do PBL o estudo independente e a busca espontânea do conhecimento, apontando ainda como um dos principais diferenciais o desenvolvimento da capacidade de aprender a aprender.

Entre as vantagens do PBL apontadas por Ribeiro (2008), o trabalho em grupo favorece maior comunicação entre os alunos, estabelecendo parcerias entre eles e os tutores - além de os alunos demonstrarem iniciativa, descobrindo o que não sabiam e procurando o que precisam para trabalhar com o problema. Segundo Venturelli (1997), a aprendizagem em pequenos grupos de tutoria promove a cooperação e o estímulo constante dos membros do grupo, permitindo a integração das dimensões biológica, psicológica e populacional, bem como a interdisciplinaridade e o raciocínio crítico.

Gil (2006) confirma essas possibilidades. O PBL não pode ser realizado com uma pessoa isoladamente; necessita de relacionamento e clima favorável entre os participantes em todas as fases do seu processo, contribuindo, dessa forma, para uma boa relação interpessoal - um dos fatores que mais influenciam a aprendizagem. Os fatores que interferem no processo de aprendizagem são: competências intelectuais, fatores emocionais, fatores sociais, motivação, concentração, reação, retroalimentação, memória e hábitos de estudo. A convivência interpessoal, praticamente, está inserida em quase todos os fatores citados.

Gomes e colaboradores (2009) publicaram uma revisão bibliográfica nas bases de dados Lilacs, Medline e nas bibliotecas Cochrane e SciELO, no período de 1998 a 2008. Utilizaram os termos medicina, graduação, aprendizagem baseada em problemas (ABP) e ensino tradicional, bem como seus correlatos em inglês, e selecionaram os que correlacionavam ensino tradicional e PBL. Entre os aspectos positivos dos cursos que adotam o 
PBL, cujos trabalhos foram encontrados nessa revisão, destacam-se a comunicação de forma eficiente, a efetivação de relacionamentos interpessoais e a atuação em equipe.

Na categoria interdisciplinaridade, houve um relato de que não existia trabalho interdisciplinar no curso de fisioterapia:

Formalmente não tem trabalho interdisciplinar. Isto quer dizer que, embora fosse um desejo nosso, uma única vez aconteceu foi em educação clínica, em que houve um projeto na comunidade em que fisioterapeutas, terapeutas ocupacionais, terapeutas da fala, cardiologista e audiologistas foram fazer a educação na comunidade e em escolas, em freguesias e em autarquias, e funcionou por dois anos e no ano de educação clínica. E neste momento não há nenhuma parte do currículo em que aconteça a interdisciplinaridade, portanto, o trabalho interdisciplinar é uma das coisas que falta cumprir (EC).

Na categoria enfoque do currículo, os alunos do $1^{\circ}$ e do $2^{\circ}$ ano afirmaram que estudavam mais a clínica e que o currículo estava começando a pensar na saúde da população. De acordo com esses alunos, até o $2^{\circ}$ ano eles não haviam visto nada sobre comunidade, e existiria um módulo de comunidade que abordaria esse assunto. Nesse sentido, os alunos do $3^{\circ} \mathrm{e}$ do $4^{\circ}$ ano relataram que contemplavam a saúde da população no módulo curricular denominado de 'fisioterapia na comunidade', e que este módulo permitia trabalhar na perspectiva de uma lógica mais preventiva. Eis o relato de um participante:

O currículo do curso, eu sei que podemos retribuir na comunidade, mas até hoje não vi nada. Sei que para a frente do curso há um módulo de que falamos da comunidade e podemos trabalhar na comunidade. Mas até agora não vimos nada e não tenho conhecimento para saber como isto funciona (EA2 $\left.{ }^{\circ} \mathrm{P}\right)$.

O modelo fragmentado não leva em conta as necessidades dos usuários e a compreensão do ser humano e do processo saúde-doença. Esse fato foi identificado na análise do bloco temático processo saúde-doença, uma vez que a saúde ainda corresponde ao modelo biomédico e se recusa a reconhecer o ser humano além de um conjunto de órgãos e sistemas que apresenta lesões ou disfunções, as quais podem ser resolvidas com técnicas.

A abordagem interdisciplinar seria uma forma de ultrapassar as fronteiras entre as disciplinas, mas os alunos relataram que existe um elo que integra várias coisas ao mesmo tempo $\left(\mathrm{Q} 1^{\circ} \mathrm{R} 2\right)$; portanto, a interdisciplinaridade no sentido de articular as disciplinas se verifica. Porém, a interdisciplinaridade no nível de articulação de diferentes profissionais da área da saúde parece não acontecer. 


\section{Conclusão}

As possibilidades apontadas no estudo que deu origem a este artigo indicaram que o PBL está em consonância com o processo de formação centrado na aprendizagem e na autonomia do aluno, mas os limites mostraram que a concepção do processo saúde-doença preconiza o modelo biomédico, desde os problemas elaborados para as sessões tutoriais até o enfoque do currículo em que a saúde pública é abordada somente em uma unidade.

A pesquisa aqui apresentada apontou indícios e reflexões de que o 'como' favorece uma metodologia pautada numa concepção progressista de educação, a qual se acredita capaz de propiciar aos alunos competências em saúde integral. Entre esses indícios e reflexões, identificamos limites e possibilidades que sugerem uma realidade na qual essa metodologia, em que os problemas são estruturados com ênfase reabilitadora, favorece um modelo tradicional e fornece aos alunos competências em saúde fragmentada e biomédica na sua formação, não contribuindo para uma formação com competências mais humanas, críticas e reflexivas. Portanto, o método por si mesmo não garante a compreensão do processo saúde-doença dentro de sua complexidade dialética. Ainda assim, reconhecemos a possibilidade do PBL como prática pedagógica em prol de uma formação mais humana e crítica, desde que seja vivenciado como um método ativo de ensino nos moldes apontados na literatura.

\section{Colaboradores}

Fabíola Hermes Chesani participou de todas as etapas de construção do manuscrito. Sylvia Regina Pedrosa Maestrelli colaborou com a correção da escrita, nos resultados e na análise das considerações finais. Luiz Roberto Agea Cutolo e Rosa Nunes colaboraram com a ideia do projeto e com a análise e discussão dos dados. 
Resumen El objetivo general del estudio fue investigar límites y posibilidades del aprendizaje basado en problemas en la formación del fisioterapeuta. El estudio se caracteriza como investigación de naturaleza cualitativa y los datos se recolectaron mediante entrevistas y cuestionarios realizados con docentes y discentes de un curso de fisioterapia, además de las observaciones en sala de aula. Los datos se analizaron por medio de análisis de contenido. Los tres bloques temáticos definidos a priori trataron de la concepción del proceso salud-enfermedad, percepción y enfoque del plan de estudios. Finalmente, indicamos como límites en la formación del fisioterapeuta la percepción del proceso salud-enfermedad, falta de bases teóricas, falta de participación de los alumnos, diferencia de personalidades y estudio individualizado. Las potencialidades señaladas se relacionan con: buena comunicación, trabajo en conjunto promoviendo habilidades profesionales, interayuda y discusión de temas, como la integración de contenidos y el estudio independiente. Este trabajo presentó indicios de que en las formaciones investigadas hay más límites que posibilidades en lo tocante a la formación de un profesional más crítico, reflexivo y humanista. Todavía no reconocemos la posibilidad del Problem-Based Learning como práctica pedagógica en pro de una formación más humana y crítica.

Palabras clave formación profesional; aprendizaje basado en problemas; fisioterapia.

\section{Notas}

${ }^{1}$ Universidade do Vale do Itajaí, Centro de Ciências da Saúde, Itajaí, Santa Catarina, Brasil. $<$ fabiola.chesani@univali.br>

Correspondência: Rua Uruguai, 458, caixa postal 360, Centro, CEP 88302-202, Itajaí, Santa Catarina, Brasil.

${ }^{2}$ Universidade Federal de Santa Catarina, Centro de Ciências Biológicas, Departamento de Biologia Celular, Embriologia e Genética, Florianópolis, Santa Catarina, Brasil. <sylviarpm@gmail.com>

${ }^{3}$ Universidade Federal de Santa Catarina, Departamento de Pediatria da Universidade Federal de Santa Catarina, Florianópolis, Santa Catarina, Brasil.

<cutolo@univali.br>

${ }^{4}$ Universidade do Porto, Faculdade de Psicologia e Ciências da Educação, Programa Doutoral em Ciências da Educação, Porto, Portugal.

<rosanunes@gmail.com>

${ }^{5}$ Este artigo faz parte da tese Limites e possibilidades do Problem-Based Learning ( $\left.P B L\right)$ na formação do fisioterapeuta, de autoria de Fabíola Hermes Chesani, defendida no Programa de Pós-Graduação em Educação Científica e Tecnológica da Universidade Federal de Santa Catarina em 2014 (Chesani, 2014). As instituições que financiaram a pesquisa foram a Coordenação de Aperfeiçoamento de Pessoal de Nível Superior (Capes) e o Fundo de Apoio à Manutenção e ao Desenvolvimento da Educação Superior (Fumdes). 


\section{Referências}

ALAMODI, Abdulhadi. Problem Based Learning sessions and undergraduate research: a medical student's perspective and experience. Perspectives on Medical Education, Maastricht, v. 3, n. 1, p. 56-60, jan. 2014.

AL-AZRI, Hammad; RATNAPALAN, Savithri. Problem Based Learning in continuing medical education: review of randomized controlled trials. Canadian Family Physician, v. 60, n. 2, p. 157-165, fev. 2014.

ALIMOGLU, Mustafa K. et al. Ways of coping as predictors of satisfaction with curriculum and academic success in medical school. Advances in Physiology Education, Bethesda, v. 35, p. 33-38, 2011.

ALMEIDA, Maria T. C.; BATISTA, Nildo A. Ser docente em métodos ativos de ensino-aprendizagem na formação do médico. Revista Brasileira de Educação Médica, Rio de Janeiro, v. 35, n. 468-476, out.-dez. 2011

Andrade, Silvia C. et al. Avaliando atitudes na graduação médica. Revista Brasileira de Educação Médica, Rio de Janeiro, v. 35, n. 4, p. 517-525, 2011.

ANYAEHIE, Ugochukwu B. et al. Medical students' evaluation of physiology learning environments in two Nigerian medical schools. Advances in Physiology Education, Bethesda, v. 35, n. 2, p. 146-148, jun. 2011.

AQUILANTE, Aline G. et al. Situações-problema simuladas. Revista Brasileira de Educação Médica, Rio de Janeiro, v. 35, n. 2, p. 147-156, 2011.

AZER, Samy et al. Introducing integrated laboratory classes in a PBL curriculum: impact on student's learning and satisfaction. BioMed Central Medical Education, Londres, v. 24, p. 13-71, maio 2013.

BARDIN, Laurence. Análise de conteúdo. Lisboa: Edições 70, 2011.

BRASIL. Anais da $8^{a}$ Conferência Nacional de Saúde. Brasília: Centro de Documentação do Ministério da Saúde, 1987. Disponível em: <http://www. ccs.saude.gov.br/cns/pdfs/8conferencia/8conf_ nac_anais.pdf > . Acesso em: 14 abr. 2014.

CANGUILHEM, Georges. O normal e o patológico. 6. ed. Rio de Janeiro: Forense Universitária, 2006.

COSTA, José R. B. et al. Metodologias ativas de ensino-aprendizagem: a visão de estudantes de medicina sobre a aprendizagem baseada em problemas. Revista Brasileira de Educação Médica, Rio de Janeiro, v. 35, n. 1, p.13-19, jan.-mar. 2011.

CUSACK, Tara; O'DONOGHUE, Grainne. The introduction of an interprofessional education module: students' perceptions. Quality in Primary Care, Abingdon, v. 20, n. 3, p. 231-238, 2012.

CZABANOWSKA, Katarzyna et al. Problem Based Learning revisited: introduction of active and self-directed learning to reduce fatigue among students. Journal of University Teaching \& Learning Practice, Wollongong, v. 9, n. 1, p. 1-13, 2012.

EFSTATHIOU, Nicolaos; WALKER, Wendy M. Interprofessional, simulation-based training in end of life care communication: a pilot study. Journal of Interprofissional Care, Abingdon, v. 28, n. 1, p. $68-70,2014$.

ESTRELA, Albano. Teoria e prática de observação de classes: uma estratégia de formação de professores. 2. ed. Lisboa: INIC, 1986.

FRANCISCHETTI, Ieda et al. Role-playing: estratégia inovadora na capacitação docente para o processo tutorial. Interface: Comunicação, Saúde e Educação, Botucatu, v. 15, n. 39, p. 1.207-1.218, out.-dez. 2011.

FURTADO, Cláudia; PEREIRA, João. Equidade e acesso aos cuidados em saúde. Lisboa: Escola Nacional de Saúde Pública, Universidade de Lisboa, julho 2010.

Recebido em 18/04/2015

Aprovado em 16/05/2016 
